\title{
Trends and transitions in the institutional environment for public and private science
}

\author{
JASON OWEN-SMITH \\ Sociology and Organizational Studies, University of Michigan, 1225 S. University Avenue \\ Ann Arbor, MI 48104-2590,U.S.A. (E-mail: jdos@umich.edu)
}

\begin{abstract}
The last quarter-century bore witness to a sea change in academic involvement with commerce. Widespread university-based efforts to identify, manage, and market intellectual property (IP) have accompanied broad shifts in the relationship between academic and proprietary approaches to the dissemination and use of science and engineering research. Such transformations are indicators of institutional changes at work in the environment faced by universities. This paper draws upon a fifteen-year panel (1981-1995) of university-level data for 87 research-intensive US campuses in order to document trends and transitions in relationships among multiple indicators of academic and commercial engagement. The institutional environment for public and private science is volatile, shifting in fits and starts from a situation conducive to organizational learning through high volume patenting to a more challenging arrangement that links indiscriminate pursuit of IP with declines in both the volume and impact of academic science. The pattern and timing of these transitions may support an enduring system of stratification that offers increasing returns to first-movers while limiting the opportunities available to universities that are later entrants to the commercial realm. Unpacking the systematic effects of university research commercialization requires focused attention on the sources and trajectories of profound institutional change.
\end{abstract}

Keywords: Institutional change, organizational environment, university, partly of license, research communication.

\section{Introduction}

The last quarter century has witnessed a dramatic expansion in the intensity and variety of university-industry relations. Far from remaining 'upstream' contributors of basic research, expertise, instrumentation, and training, universities are forging increasingly tight connections to industry through mechanisms as diverse as patenting and licensing, incubator development, equity ownership in start-up corporations, and even active venture capital investment (Association of University Techology Managers 2000; Desruisseaux 2000). These changes were catalyzed by federal and state level policies (Lee 1994; Slaughter and Rhoades 1996) and increasingly close intellectual and 
organizational connections linking cutting edge basic science to commercially valuable research in the life sciences (Owen-Smith et al. 2002; Powell and Owen-Smith 2002). Such shifts expanded through the institutionalization of organizational infrastructures for technology transfer on research intensive US campuses (Neuer 1995; Sampat and Nelson 1999).

Changes associated with academic research commercialization have been characterized as 'revolutionary' (Etzkowitz et al. 1998) and as components of the broader social 'shockwave' that stands to transform the academy and its place in society (Kerr 2002). But these alterations are not all of a piece and they do not emerge in isolation. Instead, I contend, they are outcomes of an ongoing process of institutional and organizational transformation in the arrangements and practices of universities and academic science. Such transformations are periodized, history dependent, and occur at multiple levels of analysis.

On this view, the broad effects of academic research commercialization can be found in the academy's changing position relative to government and industry (Etzkowitz and Leydesdorff 1998; Gibbons et al. 1994; Owen-Smith et al. 2002) and in transformations in the status orders and rules that govern inter-university competition (Kleinman and Vallas 2001; Owen-Smith 2003). On campus, such alterations register effects on scientific practice 'at the bench' by altering the calculus scientists use to select problems (Kleinman 1998), increasing secrecy and limiting access to research tools (Campbell et al. 2000; Heller and Eisenberg 1998), shifting standards for judging the credibility and importance of findings (Merton 1988; Packer and Webster 1996), and transforming the meanings scientists and engineers attribute to their work and careers (Etzkowitz 2003; Owen-Smith and Powell 2001a, 2001b).

In what follows I sketch the contours of academic research commercialization to argue that these changes accompany shifts in the broad relationship between public and commercial science. Changing relationships between academic and pecuniary research outputs represent an instance of macro-institutional change. I then turn to an inductive and descriptive, but quantitative, analysis of trends and transformations in the institutional environment faced by universities as they struggle to reconcile the distinct but increasingly interpellated logics of public and proprietary science. Drawing on patenting and publication data for a 15 year (1981-1995) panel of 87 research-intensive universities, I use residual correlations to examine shifting relationships between public and private science. I conclude by considering 
the implications such transformations have for theories of institutional change and for the commercial and academic endeavors of universities.

\section{Commercialization and the changing institutional environment for science}

While the origins of academic research commercialization are far flung (Geiger 1993; Mansfield 1991; Mansfield and Lee 1996; Rosenberg and Nelson 1994), an important federal policy change - the 1980 Bayh-Dole act - catalyzed widespread transformations in academic involvement with commerce. ${ }^{1}$ Bayh-Dole was intended to increase national technological and economic competitiveness by enabling non-profit organizations (including universities) and small businesses to patent the outcomes of federally funded research and development.

Under the rules set by the 1980 act, intellectual property (IP) developed on campus with federal funding must be owned by the university and transferred to the market. While many campuses were deeply involved in commerce prior to Bayh-Dole, ${ }^{2}$ the act standardized rules for university technology transfer, dramatically increased university patenting and licensing efforts, and accelerated the diffusion of organizational arrangements for the identification, management and marketing of intellectual property on campus. In organizational and institutional terms, Bayh-Dole's net result was that research intensive universities moved, en masse, into a new competitive arena characterized by commercial outputs that they were traditionally ill-equipped to manage. This move necessitated transformations in the organizational and institutional arrangements that support science and engineering research on campus (Owen-Smith 2003).

The commodification of university science has also spawned a cottage industry of academic investigation. Despite diverse disciplinary origins and methodological approaches, ${ }^{3}$ however, scholars interested in the causes and consequences of university research commercialization generally conceive of academic and commercial science as institutionally distinct fields of endeavor (Dasgupta and David 1987, 1994). The logics and rules associated with these regimes are characterized primarily in terms of the outputs of science and engineering. Patents, the coin of the commercial realm, and publications, the gold standard for the academy, are importantly different. Those distinctions are nicely captured by Rip's (1986) analogy linking patents to fences and publications to funnels. Patents, which draw on legal and bureaucratic standards of 
validation, are fences in the sense that they offer limited monopoly rights to the 'plot' of knowledge their claims demarcate. In contrast, publication funnels are typically validated through peer review processes, place findings in the public domain, and are successful precisely to the extent that they are used by others. Where the efficacy of a patent depends on its owners' ability to police their property, publications have - and to be successful can have - no expectation of exclusivity.

In this view, the primary distinction between academic and commercial science lies not in the details off daily practice but in standards of credibility, valuation, and meaning associated with different mechanisms for the dissemination and use of findings. "[W] hat matters is the socio-economic rule structures under which the research takes place, and, most importantly, what the researchers do with their findings" (Dasgupta and David 1994, p. 95). In this sense, the rationalized system of rules, conventions, and taken-for-granted assumptions embedded in intellectual property law and the peer review process represent two distinctive (and potentially contradictory) institutional models for the organization and conduct of scientific and engineering research efforts (Dimaggio and Powell 1983; Meyer and Rowan 1977). More to the point, the university and its research mission have traditionally been inseparable from academic reward systems and information disclosure conventions. Despite academe's contributions to commercial development and important reciprocal flows from industry (Mansfield and Lee 1996; Rosenberg 2000), strict separation of the institutions of academic and commercial research have made it extremely difficult, until very recently, to coherently describe the features of an 'entrepreneurial' university (but see Clark 1998).

Yet universities increasingly appear entrepreneurial in their pursuit and use of intellectual property. Commercial efforts on the part of quintessentially academic organizations may not prove broadly corrosive to non-proprietary pursuits (Mowery et al. 2001; Powell and OwenSmith 1998). ${ }^{4}$ Indeed, evidence at varied levels of analysis suggests that in some fields academic and commercial arrangements are converging on university campuses (Hicks et al. 2001; Kleinman and Vallas 2001; Owen-Smith 2003). In essence, the entrepreneurial university heralds a wider change in the institutional environments that govern research and development efforts generally as potentially contradictory and individually durable institutional systems are collapsed into a single organizational mission.

Such a collapse, I contend, offers the opportunity to observe dramatic changes in an institutional environment as established orders are 
disrupted and novel tensions - that lack taken for granted resolutions are introduced when otherwise coherent and stable arrangements are brought into prolonged contact. Such 'multiplicity' effects result in profound change precisely because long dominant and organizationally reified rule sets can lose their appearance of inevitability when applied to the same objects and contexts (Clemens and Cook 1999; Sewell 1992; Stinchcombe 1978). ${ }^{5}$ In this setting, the changing relationships among outcomes that exemplify the characteristic features of public and pecuniary science are analogous to the interstitial spaces that serve as a breeding ground for social novelty (Morrill 2004). Thus capturing the empirical shifts in relationships of convergence, independence, and substitution across academic publishing and patenting efforts can shed light upon larger patterns of institutional change. Such linkages also illumine some of the perils and possibilities of research commercialization by demonstrating the contingent effects of university patenting and publishing in light of prior activities on campus.

Whether bullish or bearish, scholars and pundits situate both the benefits and the detriments of academic research commercialization at the intersection of these distinct arrangements. Profound changes associated with commodification can be located at the inter-organizational level in shifting relationships among the inputs (particularly R\&D funding) and the outputs (particularly academic publications and patents) of university science. Thus conceptualized, larger transformations in the relationship between public and private science stand to alter both arrangements on campus and the broader environment in which universities compete for students, faculty, prestige, research support, and increasingly the rights to commercially valuable technologies.

In what follows I trace secular trends in the relationships between academic and proprietary uses of scientific findings using residual correlations. ${ }^{6}$ Changing relationships between public and private science might manifest empirically in three ways. Consider the following alternatives: (1) universities might engage in commercial activities while maintaining strict - though perhaps symbolic - segregation between academic and proprietary trajectories. ${ }^{7}$ Strong separation between upstream or 'basic' academic science and downstream or 'applied' proprietary science has provided a core organizing principle for science policy and research funding since the end of World War II (Kleinman 1995). If they remain active, such distinctions will manifest in the relative independence of commercial and academic regimes and hence of patent and publication outputs. 
On a field shaped more clearly by academic organizations' movement into the proprietary realm, (2) universities' commercial endeavors might be integrated in a more fundamental way with the pursuit of academic goals. This scenario suggests an outcome other than independence. If the relationship between public and proprietary science is corrosive to the values and practices of the academy, then patents and publications will be negatively related. If, on the other hand, commercial and academic science represent (or come to represent) mutually reinforcing regimes - as is increasingly the case in biomedicine - then patents and papers will be positively related.

Shifting relationships between public and private science outcomes reflect a changing field of play for inter-university competition. If such transitions are largely exogenous to the activities of universities - as would be the case if federal policy initiatives such as Bayh-Dole effectively generated academic research commercialization instead of accelerating it - then academic institutions will confront their changing environments in much the same fashion as athletes confront inclement weather. All players on the field will be affected in approximately the same way by factors beyond their control that necessitate adaptations in their efforts. Alternatively, change may emerge from structured patterns of action by core organizations. Here university attempts to reconcile tensions raised at the intersection of public and private science will drive changes at the level of the institutional environment. This image evokes a playing field that is progressively transformed by the strategies and efforts of players. The directions such tilts take are open to empirical scrutiny, but consider one possibility. If strategies pursued by the earliest entrants to a field exert more influence on playing conditions than the efforts of newcomers, then the playing surface will be shaped to favor incumbents, enforcing increasing returns that will be difficult for later entrants to overcome.

The alternative trajectories sketched above represent independent, substitution (negative) and complementary (positive) associations. To date these relationships have been examined using methods that estimate direct and reciprocal effects across key commercial and academic indicators. ${ }^{8}$ Such strategies typically rely on a limited set of regression coefficients for empirical support and thus face important methodological constraints on the number of and type of relationships they examine. In the interests of specifying identifiable models and controlling for unexplained variation, these approaches may miss broader shifts occurring among large sets of indicators, thus sacrificing a sense of global shifts in order to specify important correlates of 
success. I reverse the typical approach in order to establish shifting trends and timing in the institutional environment faced by researchintensive universities. Residual correlations raise interesting methodological challenges and sacrifice clear signals about the correlates of university success in favor of a wide-angle view of change.

\section{Data and methods}

Shifting relationships between public and private science accompany increased university commercialization, altering academic status competitions and mobility patterns (Owen-Smith 2003). In other words, changes that emerge from closer contact between academic and commercial science alter both the rules of the game and the environmental conditions for university competition. In order to capture the broad features of these transformations I conceptualize the institutional environment faced by universities in terms of four variables that indicate the volume and impact of academic publications and patents. Table 1 summarizes these variables and presents descriptive statistics and simple correlations for the full sample of 87 'Research 1' universities. $^{9}$

Number of patents, a measure drawn from United States Patent and Trademark Office (USPTO) database searches, captures the volume of intellectual property development on campus. ${ }^{10}$ The first row of descriptive statistics in Table 1, indicates a mean of slightly more than 12 patents per year for these universities, a figure that masks broad dispersion and a wide range. The last year of this panel (1995) is the first year in which all of the 87 universities received at least one patent. In that same year the University of California campuses at Berkeley and San Francisco successfully applied for 250 patents. $^{11}$

Wide variation in the volume of commercial science conducted on campus is matched by gulfs of impact. I use forward citations (citations from subsequent patents to a focal patent) as a measure of the impact of a university's IP. The patent citation measure, which was extracted from the National Bureau of Economic Research Patent Citation Database (Jaffe and Trajtenberg 2002), is standardized by year and technological class. Thus, a patent impact score of 1 indicates a piece of IP that was cited exactly the mean number of times as other patents of its year and technological class. The mean for the full sample of universities on this measure is 1.15 , suggesting that the patents issued to these universities are cited slightly more than the average, but that statistic also masks 

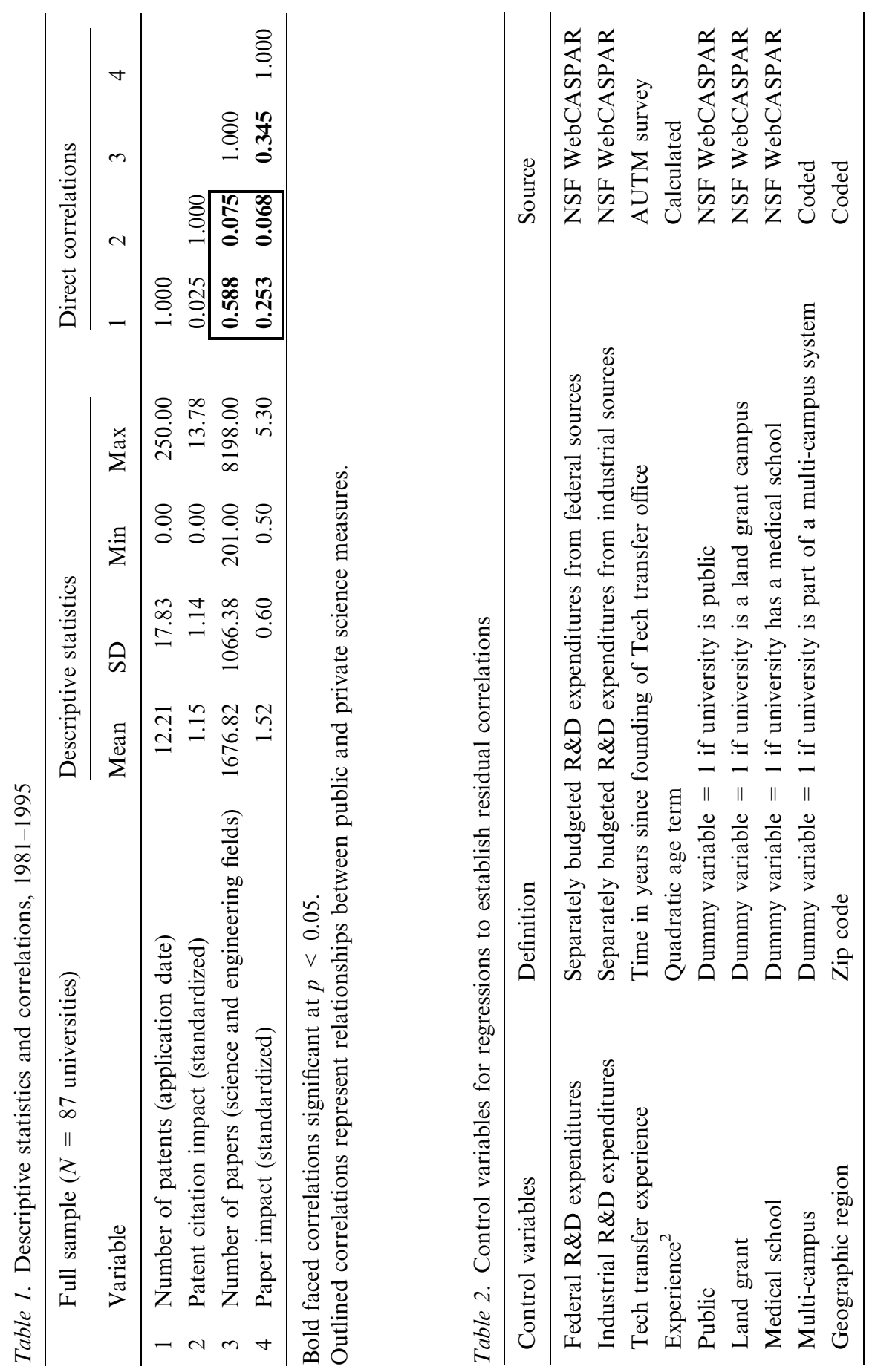
wide variation with many university patents receiving no citations and some receiving citations many standard deviations above the mean.

The two measures of academic outputs are drawn from the Institute for Scientific Information's (ISI) university indicators database. Number of papers simply measures the volume of academic science and engineering articles produced on campus. The mean is slightly more than 1600 articles with a range from 201 at the low end to more than 8100 at the high end. Paper impact is a measure of citations by subsequent articles. It too is standardized and so that the mean impact of 1.52 for the full sample represents papers cited slightly more than $50 \%$ as often as the mean for their year and field.

Turn your attention to the correlation table presented in Table 1. The outlined portion of the matrix represents the 'between realm' relationships that, I contend, can provide insight into broad relationships between academic and pecuniary science that accompany university research commercialization. Bold faced coefficients are significant at the $p<0.05$ level. Table 1 suggests that measures of public and private science volume and impact are positively and significantly related. These very correlations, however, highlight the methodological challenge inherent in untangling environmental effects from direct relationships.

\section{A methodological challenge}

Efforts to capture environmental effects must take multiple indicators into account and regression methods face important limitations in directly estimating reciprocal relationships among many variables. Thus, attempts to capture trends and transitions in associations among public and private science measures face significant challenges. A simple answer, examine patterns of correlation among key variables, founders when we take the high likelihood of spurious relationships introduced by shared organizational causes or complex interrelationships among indicators into account.

Recall Table 1. Note the strong and significant $(r=0.588)$ correlation between patent volume and paper volume. This correlation may be misleading to the extent that both patents and papers are positively related to a third factor. If, for instance, high levels of industrial R\&D support increase research capacity and thus accelerate both patenting and publishing on campus, the correlation reported in Table 1 will overestimate the actual relationship between the two variables. Economic 
research examining complementary relationships among clusters of organizational strategies, however, offers a potential solution to this dilemma; regress variables of interest on each other and on relevant organizational controls and then examine patterns of correlation among the residuals (Arora 1996; Arora and Gambardella 1990; Athey and Stern 1998).

A strategy emphasizing residual correlations examines the components of an association that cannot be explained by appeal to available variables. ${ }^{12}$ Broadly, regression analyses explain some portion of observed variance in a dependent variable as a function of variation in a set of independent variables. The difference between observed values of the dependent variable and those predicted by a given model is the residual. Generally attributed to error, the residual term in a regression results from variation that cannot be explained by the model. Correlating residuals, then, can offer insights into environmental relationships because such correlations capture covariance net of what can be explained statistically.

Speaking metaphorically, correlating the residuals of regressions estimated on multiple dependent variables for a large group of organizations is akin to checking the weather. Removing variance attributable to research-intensive universities offers a glimpse of environmental features that are not directly attributable to observable features of campuses. Establishing residual correlations among the variables described in Table 1 requires estimation of four multiple regression equations (one for each variable). Each model includes the three remaining focal variables and a set of control measures highlighted in Table 2. Estimating such equations for the full time panel (1981-1995), extracting and correlating the residuals offers a static sense of the institutional environment for university science aggregated across the entire fifteen year period.

Table 3 reprises the direct correlations reported in Table 1 and also reports residual correlations for the same variables. Once again, the relationships of interest are outlined. Where direct correlations suggest positive and significant associations among all four measures of public and private science outputs, residual correlations tell a very different story. In the aggregate, relationships among these variables net of explicable variance suggest that public and private science efforts may be at odds. Patent volume is negatively and significantly associated with publication volume and increasing patent impact is also negatively correlated with the production of basic articles in science and engineering. The impact of those articles, though, appears to be independent 
TRENDS AND TRANSITIONS IN THE INSTITUTIONAL ENVIRONMENT 101

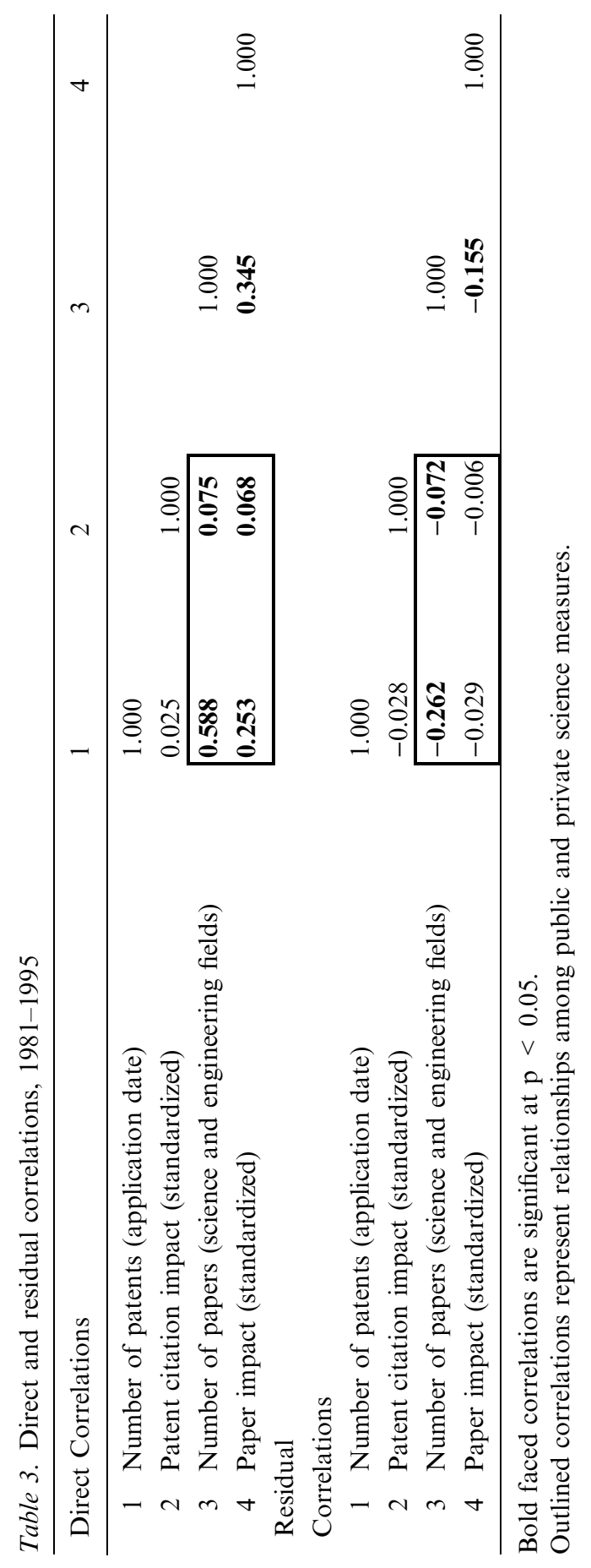


of commercial endeavors. On balance, then, Table 3 suggests that universities who patent extensively may face challenges in maintaining the volume of their basic science. These results, however, may mask important temporal variation.

\section{Observing trends and transitions}

The meat of this paper is change, but of a particular type. Attending to the durability and legitimacy of multiple overlapping institutional systems requires that attention be paid to initial conditions and to the obduracy of existing arrangements (Clemens and Cook 1999; Zucker 1977). In this sense, analyses of institutional dynamics must be sensitive to an evolutionary and history-dependent sense of change as movement from established starting points (Nelson and Winter 1982). At the same time, observations that profound institutional transformations are dramatically periodized (Scott et al. 2000) imply the necessity of determining when and how sets of relationships differ from those that preceded them. In the sections that follow, I examine residual correlations among public and private science outcomes for thirteen three-year (moving) pooled cross-sections. ${ }^{13}$ This method offers a 'smoothed' view of change without, it should be noted, indicating when a given association differs significantly from its prior value. Plotting residual relationships along a temporal axis defined by time periods offers an impressionistic view of shifting patterns of convergence and divergence across basic and proprietary science.

Figure 1 plots four associations by time period to document trends in the relationship between public and private science. These relationships are outlined in the correlation matrices presented in Tables 1 and 3. The $x$-axis in Figure 1 represents a zero correlation. Associations greater than zero suggest convergence, those less than zero suggest substitution. Correlations are plotted as $z$-scores to enable comparison across relationships.

Consider the solid black line in Figure 1, which tracks the relationship between patent and publication volume. This trend captures one of the simplest possible relationships between public and private science regimes. If increases in patenting are corrosive to an academic science system that emphasizes prompt publication of findings, then this line will tend toward the negative. In contrast, if the same mechanisms support high capacity in both article and IP outputs, then this relationship will manifest a positive tendency. Over time the trend is one of 


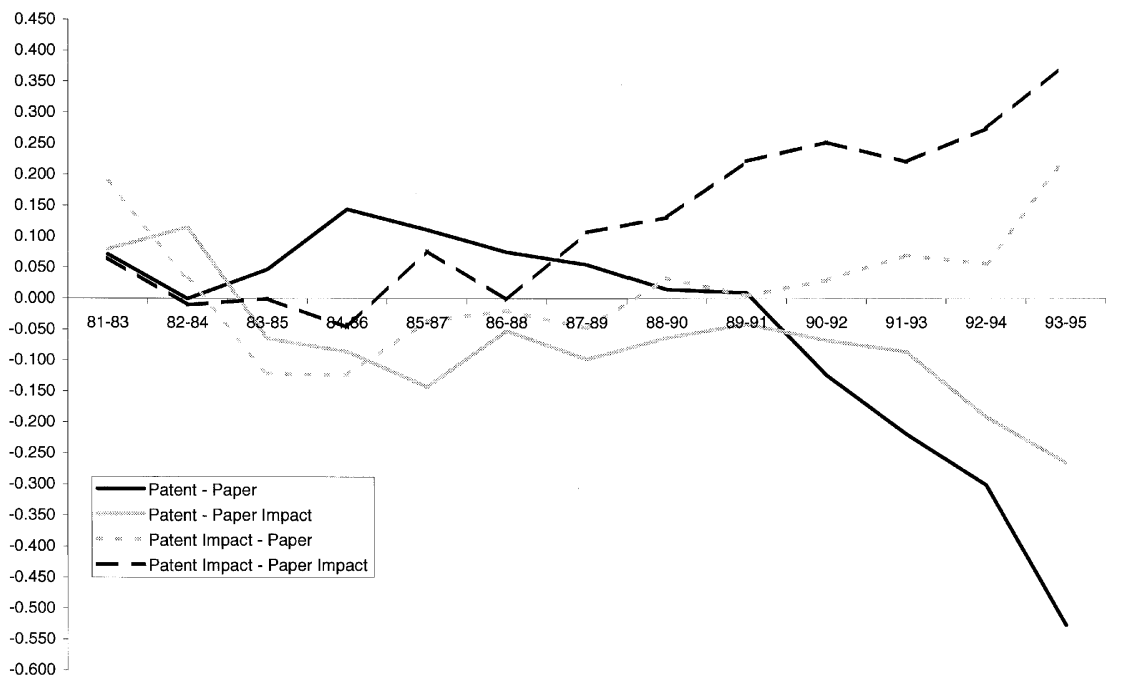

Figure 1. Trends in residual correlations, by three year moving periods.

independence or moderate complementarity until the early 1990s which see the beginnings of a steep downturn $(z=0.009$ in the 1989-1991 period and $z=-0.528$ in the $1993-1995$ period). In the terms I have been using, the period beginning in approximately 1990 is characterized by an increasingly negative environmental relationship between patent volume and publication rates.

An opposite trend is clear in the residual association between patent and publication impact - the dashed black line in Figure 1. From soon after the passage of Bayh-Dole until the mid 1980s, high impact publications and high impact patents appear relatively independent. In later time periods, however, a clear upward trend is discernable $(z=0.108$ in $1987-1989, z=0.380$ in 1993-1995). Where volume measures of public and private science diverge in the early 1990s, high impact patents and publications converge reflecting an institutional environment characterized by accumulative advantage (Merton 1968) across highly cited publications and patents. The net implication of these two trends is that universities engaged in high volume but indiscriminate patenting may see declines in publications, but those with the experience and competencies to pursue high impact patents may be able to parlay their success across academic and commercial efforts.

Two further pairs of associations link volume measures in one realm with the impact indicators of the other. The solid gray line captures the 
relationship between extensive patenting and the fecundity of academic publications while the dashed gray line reflects the association between article volume and the future impact of intellectual property. These trends, too, follow distinctively different patterns that suggest dangers linked to the indiscriminate pursuit of patents. Both trends remain mildly negative through the 1980s but they begin to diverge early in the 1990s with the relationship between patenting and publication impact tending in a more negative direction starting in the early 1990s. In contrast, the association between high impact IP and article volume shifts toward complementarity.

Figure 1 suggests that the institutional environment of public and private science bifurcates in the early 1990s. High volume patenting comes to be associated with decreases in the volume and fecundity of publications while high impact IP is linked to increases in the volume and impact of basic science outputs. For universities that patent extensively but indiscriminately a storm may be brewing. In contrast high impact patenting offers a path to leverage resources and competencies across academic and commercial endeavors. Generally, relationships between public and private science have shifted to benefit organizations with the capacity to produce, identify, and prosecute high impact innovations. In the 1990s such organizations encounter an environment where public science advantage may stem, in part, from effectively picking one's shots in the commercial realm. While these trends illumine possible outcomes of commercialization, they offer little purchase on the 'sticky' dynamics of institutional change. Thus, I turn from a focus on trends to analysis of transitions in the same set of associations.

\section{Tracking transitions}

Two classes of significance tests are necessary to establish substantively meaningful transitions in an institutional environment. The first, and more common, test determines whether a given association differs from zero. For rhetorical purposes, I dub this variety of significance test a 'cross-sectional comparison'. The benefits of a cross-sectional approach lie in its simplicity and ready interpretability. Here a statistically important shift in a relationship occurs when coefficients move from significance to independence, gain significance, or flip sign. While intuitive, cross-sectional approaches do some violence to a theoretical conception of change that emphasizes durability and the stickiness of initial conditions. 
A more conceptually satisfying approach tests differences in the same relationships across time periods. This strategy, which I call a 'longitudinal comparison, fits more closely with the theoretical sensibility underlying sociological approaches to institutional change. Longitudinal assessments of significance require that correlation coefficients ( $r$-scores) be transformed into $z$-scores, which approximate a standard normal distribution and enable statistical tests using a variant of the standard $z$-test. Residual associations differ significantly from those that preceded them if a two-tailed $z$-test fails to support the null hypothesis, $\mathrm{H}_{0}: z_{\mathrm{rl}}^{\prime}=\mathrm{z}_{\mathrm{r} 2}^{\prime}$, at the $p<0.05$ level. I implemented longitudinal tests iteratively beginning by comparing period 1 and period 2 associations. If that test failed to reject the null hypothesis period 1 was compared to period 3. The process proceeded across time periods until (and if) a significant change was uncovered. The time period that witnessed such a change became the new baseline for comparison allowing me to induce patterns of transition.

Shifts away from an initial level of association might be of two kinds. Quantitative transitions are longitudinally significant changes in magnitude without associated shifts in sign or significance. Qualitative transitions, in contrast, are longitudinally significant changes accompanied by cross-sectional shifts in sign or significance. Combining longitudinal and cross-sectional significance tests in this fashion enables analysis of when transitions occur and what kinds of changes they represent. Table 4 presents the results of these analyses for the residual correlations linking public and private science outcomes.

Table 4 highlights significant transition periods in the trends presented in Figure 1. A light gray ' $S$ ' represents a negative or substitution relationship, a dark gray ' $\mathrm{C}$ ' indicates a positive or complementary association, and a white ' $\mathrm{N}$ ' reflects a non-significant or independent correlation. Changes in color from one time period to another indicate qualitative shifts. Periods that witness quantitative transitions are outlined and signs indicate direction. When longitudinal significance tests fail to reject the null hypotheses of equality across periods, I take an association to remain the same as its baseline. To get a sense of transitions in a given relationship, pick a column and read down.

Table 4 offers an important corrective to the trends presented in Figure 1 by highlighting periodized transitions. All four 'cross-realm' relationships see significant qualitative shifts between 1981 and 1985 . Consider two key residual associations linking patent and publication volume (column 1) and the impact of articles and IP (column 4). The former begins as a complementary relationship and remains so until the 
Table 4. Qualitative and quantitative transitions in residual correlations, by moving time period

\begin{tabular}{lllll}
\hline & Patent-paper & $\begin{array}{l}\text { Patent-paper } \\
\text { impact }\end{array}$ & $\begin{array}{l}\text { Patent } \\
\text { impact-paper }\end{array}$ & $\begin{array}{l}\text { Patent } \\
\text { impact-paper } \\
\text { impact }\end{array}$ \\
\hline P1:81-83 & C & C & C & N \\
P2:82-84 & C & C & C & N \\
P3:83-85 & C & C & S & N \\
P4:84-86 & C & C & S & N \\
P5:85-87 & C & S & S & N \\
P6:86-88 & C & S & S & N \\
P7:87-89 & C & S & S & N \\
P8:88-90 & C & S & S & N \\
P9:89-91 & C & S & S & N \\
P 10:90-92 & S & S & N & C \\
P11:91-93 & S & S & N & C \\
P12:92-94 & S & S & N & C \\
P13:93-95 & S & S & C & C \\
\hline
\end{tabular}

Color changes represent qualitative transitions.

Outlined cells represent quantitative transitions.

S: Substitution relationship.

$\mathrm{S}+$ : Substitution relationship strengthened by significant $(p<0.05)$ quantitative change. C: Complementary relationship.

$\mathrm{N}$ : No relationship, independent.

early 1990s when it shifts to substitution. As the trend line suggested, the early 1990s represent a watershed for the association between patent and publication volume. Approximately a decade after Bayh-Dole, a basic relationship between public and private science shifted from being conducive to the simultaneous pursuit of patents and publications, to linking academic tradeoffs to extensive patenting. ${ }^{14}$ While the environment was changing to the potential detriment of universities whose commercial endeavors were based on high volume patenting, the judicious pursuit of high impact intellectual properties came, by the final time period, to be positively related to both publication volume and impact.

Table 4 also suggests that some time periods are particularly important transition points. The first period provides a starting point 
and four other periods (1983-1985, 1985-1987, 1990-1992, \& 19931995) witnessed qualitative shifts in public and private science relationships. If residual correlations capture important features of the universities' institutional environment, then these time periods are watersheds for understanding academic research commercialization.

To get a sense of the patterned associations that characterize a time period, pick a row and read across. The first row of Table 4 captures the initial 'field of play' in the years immediately subsequent to Bayh-Dole. In the early 1980s commercially engaged universities encountered a forgiving institutional environment where points of contact between public and private science were largely positive, suggesting the possibility of positive feedback across academic and commercial activities. Such reciprocal loops provide multiple benefits to first mover universities by facilitating the transfer of skills and capacities from one scientific production regime to another without linking commercial impact to that transfer. In simpler terms, the few years immediately following Bayh-Dole (and perhaps those that preceded it) encompass an environment highly conducive to organizational learning about a new institutional arena.

Whether it resulted from the efforts of incumbent universities, other research organizations, or forces exogenous to the academic R\&D system, a transition occurs in the 1983-1985 period. ${ }^{15}$ This cross-section differs from the preceding one primarily in that pursuing high impact patents comes at the potential expense of publication. Here, the environment still appears conducive to learning but may primarily reward high volume efforts that enable universities to develop locally appropriate arrangements for identifying and prosecuting patents rather than more focused efforts to evaluate quality. Further changes chipped away at an initial environment supportive of experimentation with commercial outputs. The 1985-1987 time period witnessed a transition in the relationship between patent volume and the impact of scientific papers. By the 1990-1992 period, the 'forgiving' environment that characterized the years immediately following Bayh-Dole had all but completely eroded as high volume patenting also became associated with decreases in publication volume and impact. This time period also saw a shift in the role played by high impact intellectual property. Where patenting extensively was negatively related to publishing efforts, Patenting judiciously with an eye toward impact came to be positively associated with high quality scientific publications.

By the final time period, the environment for public and private science had almost completely reversed its valence. Quantitative 
transitions deepened the negative association between patent and publication volume and a qualitative shift in the relationship between patent impact and publication volume formed the final link to create a new environment where the possibility for advantage to cumulate across public and private science depends upon organizational capacities to produce, identify, and prosecute high impact innovations. In the broadest possible strokes, the epochal view of change offered by this reading of Table 4 suggests an institutional environment where public and private science interfaces transition - in fits and starts - from a 'pressure system' characterized by positive returns based in output volume to one characterized by complementary association at the level of impacts.

\section{Discussion and implications}

In more practical terms, Table 4 paints an interesting picture of interuniversity competition as it suggests strong and continuing sources of advantage for campuses that made early and substantial moves to commercialize research through patenting. Initial patterns of association suggest that universities which began patenting at or before the passage of Bayh-Dole faced an environment that was particularly conducive to experimentation and learning. In a context where high volume patenting efforts were positively associated with academic endeavors, universities that patented extensively faced little academic penalty for pursuing the very activities that would allow them to develop the organizational capacities necessary to consistently leverage commercial efforts into academic returns.

Initial conditions then, may have tipped the playing field in favor of incumbents as these early entrants were able to develop the competencies and capacities necessary to allow them to shift focus to more effectively concentrate on high impact intellectual properties in later time periods. The lasting effects of an early pattern of accumulative advantage based on patent volume might be further accelerated by a later regime that linked continuing academic returns only to high impact commercial science. This further shift may have especially benefited those incumbent universities who most effectively learned to separate commercial wheat from chaff and the net effect of this pattern of environmental change may have been to generate a stratification order characterized by first-mover advantage that deepened with transitions in 
the channels for increasing returns across public and proprietary endeavors.

Such an interpretation, however, depends intimately upon the sources of the institutional transitions I trace. While establishing those sources lies well beyond the scope of this paper, descriptive data can provide some initial insights. Consider two possible sources that both postulate universities as the driving force behind their changing environment. Transformations in an institutional field may result from organizational entry. ${ }^{16}$ Research-intensive universities entered the patenting game in multiple waves. If academic institutions themselves are the driving organizational force behind the changes I document here, and if such shifts result from the actions of organizational entrants, then the transitions highlighted in Table 4 should be traceable to the efforts of newcomers. New players may carry novel strategies for managing the tensions that arise from collapsing public and private science into a single mission. Such entrants would also, presumably, benefit from the convergence between their environment and competencies that is a correlate of an entry-based theory of change.

Alternately, institutional change may come about as a result of adaptation and mimicry. A small group of universities that established successful technology transfer programs well before the passage of Bayh-Dole may have defined the rules of the game for all the organizations that followed. On this view, new entrants - especially those that lack the competencies and resources necessary for innovation - will largely mimic the arrangements of their established counterparts. Such mimicry need not be founded on the success of standard arrangements (Dimaggio and Powell 1983). Rather than effecting change in their environments, new waves of entrants would only serve to reify old sets of rules.

The lesson of this paper is that the rules of the academic game have not remained stable. If entrants increase institutional durability, and if universities are a key source of changes to their environments, then such changes are likely to emerge from organizational adaptation and innovation by the (relatively) expert and resource rich incumbents who dominate academic technology transfer efforts. Under this logic, the transitions documented in Table 4 should be foreshadowed by intraorganizational transformations among the incumbents. Here, initial entrants will continually shift the conditions of the game by adapting their efforts and innovating under conditions of organizational slack. Such a pattern of change will progressively cement their advantage, offering support for an interpretation of institutional change in public 
and private science that results in a stable stratification order characterized by increasing disparities.

If we define entry as the founding of formal infrastructure for technology transfer then universities did enter the commercial game in waves. Examining the success of incumbents, early, and later entrants may provide insights into the sources of institutional change and thus their practical implications. Table 5 presents descriptive statistics on four focal variables for three sub-samples of universities: (1) incumbents who entered prior to Bayh-Dole; (2) institutions that entered in the 1980s; (3) those that did not develop technology transfer capacity until after 1990.

A quick glance at the two measures of commercial science suggests significant disparities between incumbents and the two waves of entrants. Early entrants received almost 23 patents a year on average with less dispersion in patent impact than did either wave of newcomers. In addition incumbents appear to publish more and higher impact articles than do entrants. Two sample $t$-tests bear out these impressions. Incumbent universities are more prolific patentors and publishers than either entrant wave. Their academic outputs are also higher impact on average. Likewise, 1980s era entrants patent and publish significantly more than those who entered post-1990. In terms of patent volume, then, it appears that incumbents have a real and lasting advantage over both groups of entrants. $T$-tests support a similar pattern for both measures of academic science, but not for patent impact where there are no significant differences across classes of institutions. It is possible, that the lasting benefits of incumbency might depend on early success as well as early entry.

Table 5 provides mixed but suggestive support for a model of institutional change that depends on the actions of established players. Given the wide variation apparent even among incumbent universities, however, more fine-grained distinctions might be necessary to substantiate an adaptation-based argument and to distinguish its effects from those generated exogenously. Regardless, the strict ordering of both patent and publication volume by entry date militates against entrants as the source of transformation. Nevertheless, universities are not sole players in either science or commerce. Federal and state agencies, large and small firms from multiple sectors, and increasingly powerful professional associations may also affect the environment faced by entrepreneurial universities. In an extreme case, the changes documented here may be entirely exogenous to university activities. Environmental changes might actually approximate the effects of 
TRENDS AND TRANSITIONS IN THE INSTITUTIONAL ENVIRONMENT 111

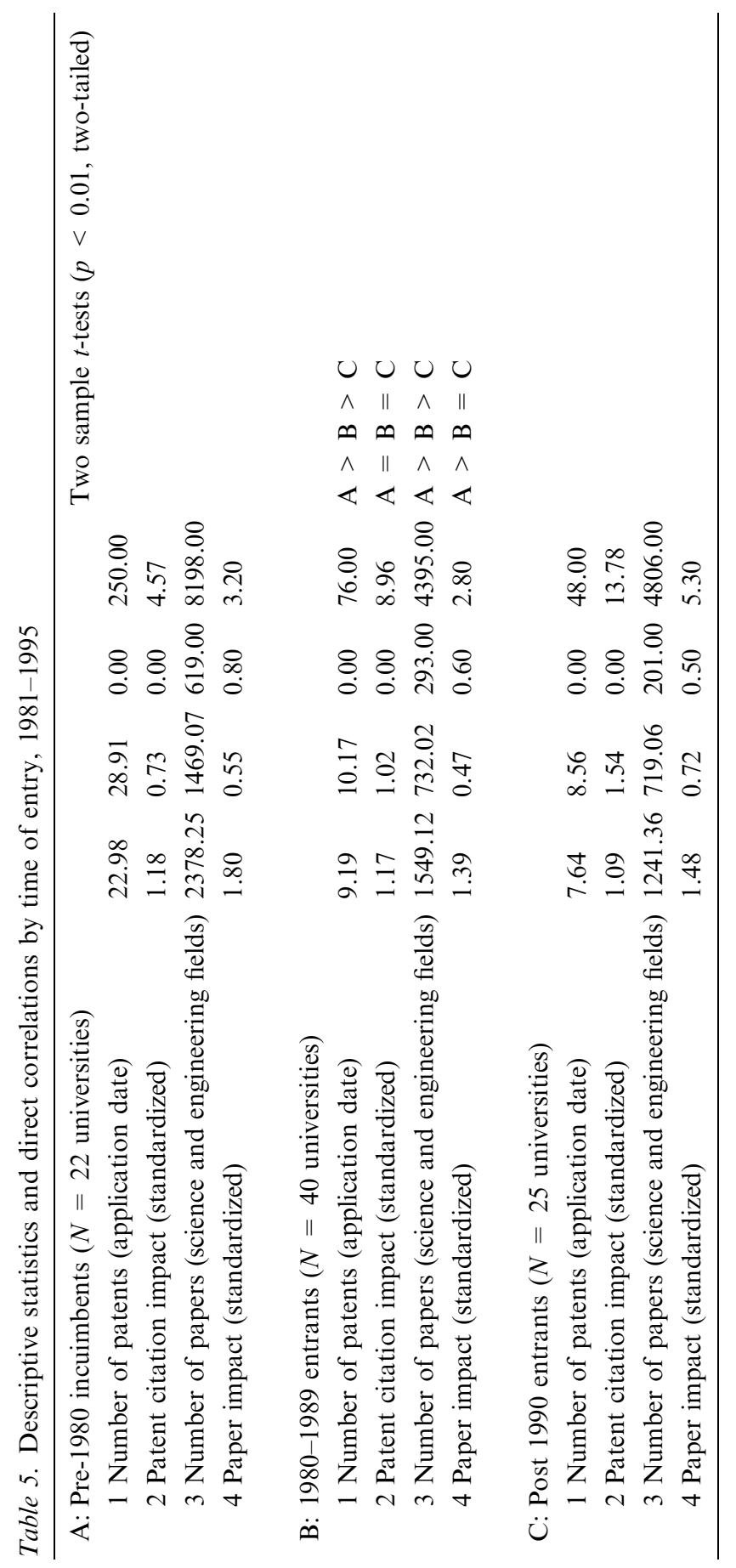


weather by making the success or failure of individual organizations contingent on their ability to adapt to prevailing conditions that are neither of their own making nor subject to their control. The institutional environment for public and private science is changing in a dramatic fashion that may have serious ramifications both for individual institutions and for the characteristic organizational arrangements and activities of academe. Untangling the implications of institutional change, however, requires further research to determine its sources.

\section{Acknowledgements}

This research was supported by the National Science Foundation (NSF Grant 0097970). This paper benefited from the thoughtful comments of Wayne Baker, Jerry Davis, John Meyer, Woody Powell, Nate Rosenberg, three anonymous reviewers for the Journal of Higher Education, and the participants at the OBHRM brown bag at the University of Michigan Business School, the SCANCOR conference on Universities and the Production of Knowledge at Stanford University, and Institutions, Conflict and Change 4 (ICC4) at Northwestern University. Any remaining mistakes are, of course, my own.

\section{Notes}

1. The actual effects of Bayh-Dole are controversial, but commentators agree that while the act did not create university commercialization it expanded and accelerated the trend toward academic engagement with commerce (Mowery et al. 2001).

2. The earliest example is the University of Wisconsin, which founded the non-profit Wisconsin Alumni Research Foundation (WARF) to commercialize faculty inventions in 1925.

3. Studies of university technology transfer range from interpretive analyses of matched patents and publications (Myers 1995) and of case law (McSherry 2001) to econometric analyses of the total factor productivity of academic licensing efforts (Thursby and Thursby 2002) and bibliometric examinations of the shifting composition of national R\&D efforts (Hicks et al. 2001).

4. But note that more subtle second order effects of research commercialization may have yet to manifest themselves and recent legal challenges to academic research exemptions (Eisenberg 2003) may remove an important (though never truly formalized) veil protecting universities from some negative implications of their own turn toward intellectual property protection.

5. The most coherent description of profound institutional change to date can be found in Scott and colleagues' (Scott et al. 2000) analysis of healthcare 
organizations in California, which argues that such changes result in the relatively rapid rise of new actors, logics, meanings, relationships and conceptions of an organizational field. My emphasis on the characteristic outputs of two durable institutional systems emphasizes logics, meanings, and relationships over new organizational or collective efforts.

6. Note that I define academic and commercial 'uses' primarily in terms of funding sources and dissemination mechanisms rather than by the type of organization producing the findings. On this view a finding supported by NIH funding and published in a peer reviewed journal represents 'basic science' whether the research was conducted in corporate, academic, government, or non-profit research environments.

7. This logic underpinned early public university entrants' tendency to administer patenting and licensing arrangements off campus through separate non-profit organizations. The most notable example of this approach is WARF.

8. Such analyses typically draw on some combination of patent, publication, funding, and reputational data (Agrawal and Henderson 2002; Owen-Smith 2003; Sine et al. 2003).

9. Research One is a designation of research intensity that was applied to academic institutions by the Carnegie Commission on Higher Education. In order to qualify for Research One status an institution had to grant at least 50 doctorates and receive more than $\$ 40$ million of federal $R \& D$ funding annually. The Carnegie classification system was recently changed but prior to the transition 89 US universities qualified as Research One institutions. Missing data on academic outputs prevents the inclusion of two universities (Howard University and Yeshiva University) in these analyses.

10. Patents are time stamped by their application date rather than their issue date to avoid complications introduced by variable lags in the patent examination process (Jaffe and Trajtenberg 2002).

11. Because the University of California system, like many multi-system campuses, administers patents from a central location, patents were assigned to individual campuses by appeal to the address of the first inventor. It was not possible using this technique to distinguish between UC-Berkeley and UCSF, so the campuses were combined.

12. This approach is uncommon in quantitative sociology with the exception of large scale statistical studies of inequality where residuals in exceptionally well specified models are often attributed to the unobservable effects of discrimination (England 1992).

13. Where the matrices reported in Table 2 represent relationships across an entire fifteen year pool and hence assume there are no significant changes across time periods, independently estimating residual correlations in three year moving windows documents trends while maintaining a reasonable sample size $(N=261$ University-years) in each pool. I define the time periods starting in 1981 (the year immediately following the passage of Bayh-Dole as follows: Period 1: 1981-1983, Period 2: 1982-1984 ... Period 13: 1993-1995. For each time period I estimate four OLS regressions on the focal variables defined in Table 1. Each model includes the controls defined in Table 2 and the remaining focal variables. The result is a set of 13 residual correlation matrices that can be 'stacked' to represent system level trends in public and private science relationships. 
14. Quantitative shifts strengthening this relationship occurred in the mid-1990s suggesting that the negative association between indiscriminate patenting and article publication is becoming stronger.

15. Residual correlations derived from regressions, which control for all inter-university variation (using university fixed effects) manifest almost complete independence among measures and no discernable trends in residual correlations, suggesting that the changes observed here are a result of unobserved variation across universities. It is possible, then, that the changing environment described here is altered primarily by the actions of academic institutions as they enter the commercial arena and pursue pecuniary science outcomes. Results of these models are available from the author upon request.

16. In principle, such changes could also be a result of failure or exit. Large universities, however, rarely fail or merge and, as yet, few have withdrawn entirely from commercial endeavors. Thus, I do not consider this possibility.

\section{References}

Agrawal, A. and Henderson, R. (2002). 'Putting patents in context: Exploring knowledge transfer from MIT', Management Science 48, 44-60.

Arora, A. (1996). 'Testing for complementarities in reduced-form regressions: A note', Economics Letters 50, 51-55.

Arora, A. and Gambardella, A. (1990). 'Complementarity and external linkages - the strategies of the large firms in biotechnology', Journal of Industrial Economics 38, 361-379.

Association of University Techology Managers. (2000). 'Licensing Survey, FY 2000: Full Report', Association of University Technology Managers.

Athey, S. and Stern, S. (1998). 'Am Empirical Framework for Testing Theories about Complementarity in Organizational Design', NBER Working Paper \#6600.

Campbell, E.G., Weissman, J.S., Causino, N. and Blumenthal, D. (2000). 'Data withholding in academic medicine: characteristics of faculty denied access to research results and biomaterials', Research Policy 29, 303-312.

Clark, B.R. (1998). Creating Entrepreneurial Universities: Organizational Pathways of Transformation. Oxford; New York: Published for the IAU Press by Pergamon Press.

Clemens, E.S. and Cook, J.M. (1999). 'Politics and institutionalism: Explaining durability and change', Annual Review of Sociology 25, 441-466.

Dasgupta, P. and David, P.A. (1987). 'Information disclosure and the economics of science and technology', in Feiwel, G.R. (ed.), Arrow and the Ascent of Modern Economic Theory. New York: University Press, pp. 659-589.

Dasgupta, P. and David, P.A. (1994). 'Toward a new economics of science', Research Policy 23, 487-521.

Desruisseaux, P. (2000). 'Universities venture into venture capitalism', Chronicle of Higher Education, 5/26/2000, A44.

Dimaggio, P.J. and Powell, W.W. (1983). 'The iron cage revisited - Institutional isomorphism and collective rationality in organizational fields', American Sociological Review 48, 147-160.

Eisenberg, R.S. (2003). 'Science and the law - Patent swords and shields', Science 299, $1018-1019$ 
England, P. (1992). Comparable Worth: Theories and Evidence. New York: Aldine De Gruyter.

Etzkowitz, H. (2003). 'Research groups as 'quasi-firms': the invention of the entrepreneurial university', Research Policy 32, 109-121.

Etzkowitz, H. and Leydesdorff, L. (1998). 'The endless transition: A 'triple helix' of university-industry-government relations', Minerva 36, 203-208.

Etzkowitz, H., Webster, A. and Healey, P. (1998). Capitalizing Knowledge: New Intersections of Industry and Academia. Albany, NY: State University of New York Press.

Geiger, R.L. (1993). Research and Relevant Knowledge: American Research Universities since World War II. NY: Oxford University Press.

Gibbons, M., Nowotny, H., Limoges, C., Trow, M., Schwartzman, S. and Scott, P. (1994). The New Production of Knowledge. London: Sage.

Heller, M.A. and Eisenberg, R.S. (1998). 'Can patents deter innovation? The anticommons in biomedical research', Science 280, 698-701.

Hicks, D., Breitzman, T., Olivastro, D. and Hamilton, K. (2001). 'The changing composition of innovative activity in the US - a portrait based on patent analysis', Research Policy 30, 681-703.

Jaffe, A.B. and Trajtenberg, M. (2002). Patents, Citations, and Innovation: A window on the knowledge economy. Cambridge, MA: MIT Press.

Kennedy, D. (2003). 'Industry and academia in transition', Science 302, 1293-1293.

Kerr, C. (2002). 'Shockwave II: An Introduction to the 21st Century', in Brint, S.G. (ed.), The Future of the City of Intellect. Stanford: Stanford University Press, pp. 1-19.

Kleinman, D.L. (1995). Politics on the Endless Frontier: Postwar Research Policy in the United States. Durham: Duke University Press.

Kleinman, D.L. (1998). 'Untangling context: Understanding a university laboratory in the commercial world', Science, Technology, and Human Values 23, 285-314.

Kleinman, D.L. and Vallas, S.P. (2001). 'Science, capitalism, and the rise of the 'knowledge worker': The changing structure of knowledge production in the United States', Theory and Society 30, 451-492.

Lee, Y.S. (1994). 'Technology-transfer and public-policy in an age of global economic competition - introduction to the symposium', Policy Studies Journal 22, 260-266.

Mansfield, E. (1991). 'Academic research and industrial-innovation', Research Policy 20, $1-12$.

Mansfield, E. and Lee, J.Y. (1996). 'The modern university: Contributor to industrial innovation and recipient of industrial R\&D support', Research Policy 25, 1047 1058.

McSherry, C. (2001). Who Owns Academic Work?: Battling for Control of Intellectual Property. Cambridge, Mass: Harvard University Press.

Merton, R.K. (1968). 'The Matthew effect in science', Science 159, 56.

Merton, R.K. (1988). 'The Matthew effect in science 2. cumulative advantage and the symbolism of intellectual property', Isis 79, 606-623.

Meyer, J.W. and Rowan, B. (1977). 'Institutionalized organizations - formal-structure as myth and ceremony', American Journal of Sociology 83, 340-363.

Morrill, C. (2004). 'Institutional change through interstitial emergence: The growth of alternative dispute resolution in american Law, 1965-1995', Forthcoming in Powell, W.W. and Jones, D.L. (eds.), How Institutions Change. Chicago: University of Chicago Press. 
Mowery, D.C., Nelson R.R., Sampat, B.N. and Ziedonis, A.A. (2001). 'The growth of patenting and licensing by US universities: an assessment of the effects of the BayhDole act of 1980', Research Policy 30, 99-119.

Myers, G. (1995). 'From discovery to invention - the writing and rewriting of 2 patents', Social Studies of Science 25, 57-105.

Nelson, R.R. and Winter, S.G. (1982). An Evolutionary Theory of Economic Change. Cambridge, Mass: Belknap Press of Harvard University Press.

Neuer, A. (1995). 'Academic technology transfer offices evolve into marketing units', The Scientist 9, 1-4.

Owen-Smith, J. (2003). 'From separate systems to a hybrid order: accumulative advantage across public and private science at Research One universities', Research Policy 32, 1081-1104.

Owen-Smith, J. and Powell, W.W. (2001a). 'Careers and contradictions: Faculty responses to the transformation of knowledge and its uses in the life sciences', The Transformation of Work, a special issue of Research in the Sociology of Work 10, $109-140$.

Owen-Smith, J. and Powell, W.W. (2001b). 'To patent or not: Faculty decisions and institutional success in academic patenting', Journal of Technology Transfer 26, 99-114.

Owen-Smith, J., Riccaboni, M., Pammolli, F. and Powell, W.W. (2002). 'A comparison of US and European university-industry relations in the life sciences', Management Science 48, 24-43.

Packer, K. and Webster, A. (1996). 'Patenting culture in science: Reinventing the scientific wheel of credibility', Science, Technology, and Human Values 21, 227-253.

Powell, W.W. and Owen-Smith, J. (1998). 'Universities and the market for intellectual property in the life sciences', Journal of Policy Analysis and Management 17, 253-277.

Powell, W.W. and Owen-Smith, J. (2002). 'The new world of knowledge production in the life sciences', in Brint, S.G. (ed.) The Future of the City of Intellect. Stanford: Stanford University Press, pp. 107-132.

Rip, A. (1986). 'Mobilizing resources through texts', in Callon, M. (ed.), Mapping the Dynamics of Science and Technology: Sociology of Science in the Real World. Houndmills, Basingstoke, Hampshire: The Macmillan Press.

Rosenberg, N. (2000). Schumpeter and the Endogeneity of Technology: Some American Perspectives. London; New York: Routledge.

Rosenberg, N. and Nelson, R.R. (1994). 'American universities and technical advance in industry', Research Policy 23, 323-348.

Sampat, B.N. and Nelson, R.R. (1999). The Emergence and Standardization of University Technology Transfer Offices: A Case Study of Institutional Change. New York: Columbia University.

Scott, W.R., Ruef, M., Mendel, P.J. and Caronna, C.A. (2000). Institutional Change and Healthcare Organizations: from Professional Dominance to Managed Care. Chicago: University of Chicago Press.

Sewell, W.H. (1992). 'A theory of structure - duality, agency, and transformation', American Journal of Sociology 98, 1-29.

Sine, W.D., Scott, S. and Di Gregorio, D. (2003). 'The halo effect and technology licensing: The influence of institutional prestige on the licensing of university inventions', Management Science 49, 478-496. 
Slaughter, S. and Rhoades, G. (1996). 'The emergence of a competitiveness research and development policy coalition and the commercialization of academic science and technology', Science, Technology, and Human Values 21, 303-339.

Stinchcombe, A.L. (1978). Theoretical Methods in Social History. New York: Academic Press.

Thursby, J.G. and Thursby, M.C. (2002). 'Who is selling the Ivory Tower? Sources of growth in university licensing', Management Science 48, 90-104.

Zucker, L.G. (1977). 'Role of institutionalization in cultural persistence', American Sociological Review 42, 726-743. 